\title{
People-to-People-to-Geographical-Places: The P3 Framework for Location-Based Community Systems
}

\author{
QUENTIN JONES ${ }^{1}$, SUKESHINI A. GRANDHI $^{1}$, LOREN TERVEEN $^{2}$ \\ \& STEVE WHITTAKER ${ }^{3}$ \\ ${ }^{1}$ Department of Information Systems College of Computing Sciences, New Jersey Institute of \\ Technology, University Heights Newark, New Jersey 07102, USA (Email: \{qjones, \\ sg49\}@njit.edu); ${ }^{2}$ Department of Computer Science and Engineering, University of Minnesota, \\ 4-192 EE/CS Building, 200 Union Street SE, Minneapolis, MN 55455, USA (E-mail: \\ terveen@cs.umn.edu); ${ }^{3}$ Department of Information Studies, University of Sheffield, Western \\ Bank, Sheffield S10 2TN, UK (E-mail: s.whittaker@sheffield.ac.uk)
}

\begin{abstract}
In this paper we examine an emerging class of systems that link People-to-People-toGeographical-Places; we call these P3-Systems. Through analyzing the literature, we have identified four major P3-System design techniques: People-Centered systems that use either absolute user location (e.g. Active Badge) or user proximity (e.g. Hocman) and Place-Centered systems based on either a representation of people's use of physical spaces (e.g. ActiveMap) or on a matching virtual space that enables online interaction linked to physical location (e.g. Geonotes). In addition, each feature can be instantiated synchronously or asynchronously. The P3-System framework organizes existing systems into meaningful categories and structures the design space for an interesting new class of potentially context-aware systems. Our discussion of the framework suggests new ways of understanding and addressing the privacy concerns associated with location aware community system and outlines additional socio-technical challenges and opportunities.
\end{abstract}

\section{Introduction}

The promise of context-aware computing, as originally conceptualized, was the development of systems that sense aspects of their environment in order to "adapt according to the location of use, the collection of nearby people, hosts, and accessible devices, as well as to changes to such things over time" (Schilit et al., 1994). In other words, the "context" of a context-aware system was relevant people, places, and things in its physical environment. Over time, researchers tried to include more contextual information in systems, including richer aspects of the physical environment (Brown et al., 1997) and users' physical, social, emotional, or informational state (Dey, 1998). Similarly, the functions that context-aware applications may implement were expanded to include: (1) the presentation of contextualized information and 
services; (2) context based automatic execution of services; and (3) the attaching of contextual information for later retrieval (Dey et al., 2001).

Considering the broadness of the term "context-awareness", it is difficult for any single research effort to engage the term as a whole. Instead, we believe it is necessary to focus on smaller functional definitions. This is what we do here, by exploring systems that link People-to-People-to-Geographical-Place, which we refer to as P3-Systems (Jones and Grandhi, 2004). In this way we focus on systems concerning the people and places of Schilit et al.'s (1994) original context-aware definition. While not all P3-Systems are context-aware applications in the sense of "adapting" according to the context of use (Schilit et al., 1994), they nevertheless all provide contextual information through different functions as described above. A number of systems that have been labeled "context-aware" have also been labeled "community applications", as they highlight and utilize people's connections to each other in physical space. Examples of such systems include Active Badge (Want and Hopper, 1992; Want et al., 1992) and Active Map (McCarthy and Meidel, 1999), which allow people to locate others within buildings and various digital graffiti systems (e.g. E-Graffiti; Burrell and Gay, 2001) which associate digital information with physical locations.

As we shall detail, there are a growing number of P3-Systems and a diversity of approaches. However, the area lacks a firm foundation; in particular, there is no agreed-upon conceptual framework for describing the design space. Without such a framework, it is difficult to characterize precisely what different systems have in common, let alone to explore systematically the range of possible designs. A framework can identify key challenges and suggest important research opportunities. As our later discussion shows, many existing P3-Systems do not adapt according to the user's physical and or social environment, and are thus not context-aware applications. This shows both how the P3-System framework takes a different perspective on the design space, and highlights the need for a more thorough examination of how these systems can be made adaptive to their context (particularly in regards to the management of the sharing of personal location data which is discussed in detail in Section 5).

The remainder of the paper is organized as follows. We first briefly examine the relationship between place and people's social behavior. We next present our analytic framework for organizing the P3-System design space, introducing the dimensions that define the space and discussing prominent existing systems that illustrate different points of the space. We then show how the framework can help guide design and research. We do this by first identifying a few key tasks P3-Systems support and how they tie to the framework. We then show how the framework and associated tasks can be used to inform our understanding of privacy issues for P3-Systems. We conclude with a discussion of how the framework highlights major socio- 
technical and design challenges that confront the development and deployment of P3-Systems.

\section{People and places}

The relationship between people and places has been addressed by research on "community". This research indicated that historically people's interactions and social relations were highly local, grounded in and organized around shared physical space. People got together to talk. They lived their lives within a few miles of where they were born, forming friendships, marrying, raising their children, and dying. A wave of writing by community theorists at the beginning of the 1960s took these place-mediated interactions as essential to a social relations/community (Nelson et al., 1960; Stern, 1960). In fact, authors considered increased physical mobility and use of technology as a threat to community itself (Nelson et al., 1960; Stern, 1960).

However, the emergence of "online communities" in the 1960s (with the early Internet - see Hiltz and Turoff, 1978) showed that social relations could be separated from shared physical space. It is possible to develop relationships and form groups (Gillepsie and Williams, 1988; Wellman et al., 2001), even if the "lower bandwidth" of computer-mediated communication channels makes this process take longer (Walther, 1992; Walther et al., 1994; Parks and Roberts, 1998).

Online communities have been the target of much technical innovation and research. One major line of work is based on the idea of a social network, which represents groups of people and relationships between them. Sociologists formalized this intuitive notion, using mathematical graph theory to represent and analyze concepts such as the strength of social ties, central and peripheral social roles, information flow, and access to resources (Granovetter, 1973; Wasserman and Faust, 1994; Freeman, 1998). These techniques also have been used to analyze computer-mediated communication (e.g. Garton et al., 1997).

Many software applications have either built directly on, or have been inspired by, social network analysis. Whittaker et al. (2004) designed a system for communication and contact management based on the idea of a personal social network. Kautz et al. (1997) and McDonald (2003) created expertise recommenders that used social networks to find experts who were socially close to an information seeker. Several researchers (Donath et al., 1999; Sack, 2000; Smith and Fiore, 2001) have designed social visualization tools that graphically depict structural information about online discussion groups, including relationships derived from communication patterns. Other researchers have created social matching systems (Terveen and McDonald, forthcoming) to help people form new relationships and extend networks. 
More recently, commercial artificial/pseudo 'social network' tools such as Friendster, Orkut, Tribe, LinkedIn, Huminity, and Spoke have built on ideas from all these areas, allowing users to create, browse, message to, and extend friendship networks. There also are open source projects (e.g. foaf.org) that allow people to represent interpersonal relationship data in a machine-readable format.

While the work on online communities clearly is productive, our focus here is on community and social software that re-establishes the connection to physical place. This emphasis is based on the realization that there are a number of important ways in which physical places affect and influence social behavior, including the following:

(1) A shared physical environment promotes informal social communication (Kraut et al., 1990; Whittaker et al., 1994). Physical proximity increases the likelihood of impromptu social conversations and of forming relationships (Whyte, 1956). Many organizations exploit this in the design of their workplaces, e.g. by designing shared public spaces where people can "bump into each other".

(2) Places can also help to co-ordinate complex social activities. Extensive research on awareness has shown how peripheral information about the conversations and actions of others can help people manage complex team activities (Cadiz et al., 2002).

(3) Places constrain and afford activities. Places are simultaneously configured for certain activities and make it hard for other activities that are non-typical to the place to occur (Genereux et al., 1983; Kramer, 1995). For example, a pub might support socializing, a church worship and perhaps community meetings, and a neighborhood store buying necessities and maybe running into friends and neighbors.

(4) Places act as social filters for people. Not everyone goes to every place, making some places familiar and safe for certain people but not others. This holds true even for people who do not explicitly "know" each other (cf. Milgram's notion (1977) of the "familiar stranger"). This also means that the best way to socialize with certain people may be to visit the places they frequent.

Not only are individual places important, there also are many situations in which increased or improved communication within a local geographical context is desirable. For example, a university administrator may see increased communication between students, faculty, and staff as beneficial to campus life. Informal communication between different levels of employees has been demonstrated to be important for innovation in high-tech companies (Allen, 1977). Similarly, neighborhood and community activists may consider increased interactions between local residents valuable.

Over the past decade, the emergence of new location technologies has enabled the re-connection of community software to physical place. For 
example, the Global Positioning System (GPS) allows users to be located outdoors, and other technologies from WiFi triangulation to active badges to video sensing allow users to be located indoors. In other words, new technology enables systems to incorporate two of the original and fundamental aspects of context-aware computing - place and people - in new and powerful ways.

\section{The P3 framework: Systems that link people-to-people-to-geographic-place}

A framework that defines the design space for a class of systems serves analytic and design purposes. It enables better understanding and comparison of existing designs as well as identifying opportunities for new exploration and research. First, however, the class of systems under discussion must be recognized as distinct. Until recently, information systems that systematically link people-to-people-to-geographic-place have not been taken as a distinct category (Jones and Grandhi, 2004). This may be due to the relatively recent availability of the enabling technology, the variety of different techniques prototyped, and the number of different sub-areas - each with its own conferences and journals - in which work has been done. So, while terms such as "context-aware", "location-based services", "pervasive computing", "proximity computing", "augmented reality", "virtual reality", "mixed reality", and "teleportation" capture certain technologies and perspectives, they do not reveal the functional similarities of these systems.

We believe - and we detail below - that sufficient development has occurred to justify the use of the new collective term, P3-Systems. Our proposal of P3-Systems - people-to-people-to-geographic-place - characterizes the class of systems as essentially community systems (people-to-people) that are tightly organized around and utilize the notion of geographic place.

The P3-Systems conceptual framework defines a $2 \times 2$ design space (Table I). The first dimension distinguishes People-Centered techniques from Place-Centered techniques. ${ }^{1}$ People-Centered techniques use location information to support interpersonal awareness, enable informal communication, and identify previously unknown affinities between users. Place-Centered techniques link virtual spaces to physical locations, using social information to aid place-based navigation and decision making.

Both People-Centered and Place-Centered techniques can be subdivided, each along a different dimension. Some People-Centered techniques use absolute user locations, while others use relative location or proximity between users. The difference here is between applications that tell users where their buddies are and those that only tell users which buddies are close by. The term "buddies" is used to describe a privileged set of individuals whom the users want to monitor. Some Place-Centered techniques represent 
Table I. The P3-Systems framework techniques summary

\begin{tabular}{|c|c|c|c|}
\hline & $\begin{array}{l}\text { P3-system } \\
\text { design } \\
\text { approaches }\end{array}$ & $\begin{array}{l}\text { Synchronous } \\
\text { communication or } \\
\text { location awareness }\end{array}$ & $\begin{array}{l}\text { Asynchronous } \\
\text { communication or } \\
\text { location awareness }\end{array}$ \\
\hline \multirow[t]{2}{*}{$\begin{array}{l}\text { People- } \\
\text { Centered }\end{array}$} & $\begin{array}{l}\text { Absolute user } \\
\text { location }\end{array}$ & $\begin{array}{l}\text { (1) Utilizes remote awareness } \\
\text { of current user location }\end{array}$ & $\begin{array}{l}\text { (2) Utilizes people's loca- } \\
\text { tion histories }\end{array}$ \\
\hline & $\begin{array}{l}\text { Co-location / } \\
\text { Proximity }\end{array}$ & $\begin{array}{l}\text { (3) Utilizes real-time user } \\
\text { co-location for the } \\
\text { exchange of social } \\
\text { information }\end{array}$ & $\begin{array}{l}\text { (4) Utilizes co-location } \\
\text { history to enable future } \\
\text { interactions }\end{array}$ \\
\hline \multirow[t]{2}{*}{$\begin{array}{l}\text { Place- } \\
\text { Centered }\end{array}$} & $\begin{array}{l}\text { Use of physical } \\
\text { spaces by people }\end{array}$ & $\begin{array}{l}\text { (5) Utilizes online } \\
\text { representation of user's } \\
\text { current use of physical } \\
\text { spaces }\end{array}$ & $\begin{array}{l}\text { (6) Utilizes history of } \\
\text { people's use of a particu- } \\
\text { lar space }\end{array}$ \\
\hline & $\begin{array}{l}\text { Use of matching } \\
\text { virtual Places }\end{array}$ & $\begin{array}{l}\text { (7) Utilizes synchronous } \\
\text { online interactions } \\
\text { spaces related to physical } \\
\text { location }\end{array}$ & $\begin{array}{l}\text { (8) Utilizes asynchronous } \\
\text { online interactions related } \\
\text { to physical location }\end{array}$ \\
\hline
\end{tabular}

people's current or past use of a physical location (e.g. showing who is on a university campus now) and others associate a virtual space with a physical location such as traditional community networks.

The final dimension is an extension of the standard CSCW distinction between synchronous and asynchronous interaction. We go beyond the traditional application of the distinction to include user-location information. Thus, we also refer to synchronous and asynchronous "location awareness" to distinguish techniques that provide information about current user location or activity within a place from those that provide historical information. This location awareness is however not intrinsically reciprocal even in synchronous situations: a system could provide a user with a buddy's location without providing the buddy with the user's location. Synchronous communication and location awareness data are created with the expectation that they will be processed in real (or near) real time, while asynchronous communication and location awareness data are produced with the expectation of an unpredictable delay between data creation and consumption. Therefore, synchronous and asynchronous applications can be viewed as two ends of a continuum, rather than as discrete alternatives.

Application of these distinctions generates an eight cell table. We now consider the eight different types of system techniques, illustrating each 
through a discussion of several prominent systems that implements the techniques. Note that a particular system may implement multiple techniques.

\subsection{PEOPLE-CENTERED: ABSOLUTE USER LOCATION: SYNCHRONOUS}

Active Badge (Want and Hopper, 1992; Want et al., 1992), one of the earliest $\mathrm{P} 3$-Systems, provides real-time information about user locations, and the system's FIND command can be used to illustrate the absolute user location technique. Conceived, designed, and prototyped between 1989 and 1992, individuals wear an "active badge" that tracks their location within an appropriately equipped building. The badge implements location tracking by transmitting a unique infra-red signal every 10-15 seconds that is detected by one or more networked sensors. Using the FIND command, a user can query another user to find both their current location and a list of all locations they have been reported at in the last 5 min.

Active Badges were designed to facilitate communication. For example, phone calls could be routed to the phone nearest to an individual based on the last reported location. The system also provided an online community space that could be used to locate users without using a public-address system or telephoning all possible locations at which they might be found.

Absolute user location techniques can enhance various applications. For example, the "status" information for a buddy in an IM client can be augmented with the buddy's location (e.g. the Lemming application of Hong and Landay, 2004). Some commercial services already allow tracking of specified mobile phone numbers in a community context. For example, Ulocate (http:// www.Ulocate.com/) is designed to let family members track each others' location on a map. Note that such tracking applications become P3-Systems only when they enable sharing of information within a community of users. Therefore, for example, the current version of GPSTracks, the pet tracking application http://www.gpstracks.com/ would not be considered a P3-System.

The absolute user location technique can also be reversed to describe incoming communication rather than remote sensing. In this case, rather than one user seeking the location of another with or without initiating interaction, the technique can be used to provide location information to the recipient of incoming communication about the remote initiator of an interaction.

\subsection{PEOPLE-CENTERED: ABSOLUTE USER LOCATION: ASYNCHRONOUS}

A number of systems implement techniques from this category. Examples include: Ulocate's history function, group calendars that describe the location 
of individuals over time, and some moblogs (mobile phone web logs) that contain time- and location-stamped pictures. In a sense all these applications have similar functions to group calendars (Palen and Grudin, 2002). The aim is to provide information about past (and possibly future) locations of a set of buddies. Such information can be used for scheduling, coordinating meetings and some security applications.

\subsection{PEOPLE-CENTERED: PROXIMITY: SYNCHRONOUS}

This category has been explored by quite a few commercial systems as well as research prototypes. The Cybiko (www.cybiko.com) device uses radio frequency communication to let nearby individuals interact electronically. The Hummingbird device supports social awareness between co-located people (Weilenmann and Holmquist, 1999). It gives group members continuous auditory and visual indications of other group members in the vicinity. These cues are designed to enhance opportunistic face-to-face interactions.

Meme Tags and Community Mirrors (Borovoy et al., 1998) also support synchronous interaction between co-located people. The system includes both a personalized online space (individual Meme-Tags) and a community space (Community Mirrors). A "meme" is an idea or opinion realized as a short piece of text. Users can create their own memes and share them with other nearby users. Community Mirrors convey a variety of information about inter-user meme exchanges in near real time. They display the meme texts, popular and dying ideas, as well as information about group dynamics, such as the "cliquishness" of the gathering. Community Mirrors also give users a sense of what other participants know. The goal of system design here is to facilitate the formative stages of interaction by giving people common reference points for conversation. To a similar end, Neighborhood Window (McCarthy et al., 2003) used active badge technology to identify users standing in front of a large display, compute shared interests of these users, and then depict them on the display.

Co-location can also be used specifically for social matching, bringing people together for interaction and potentially new relationships (Terveen and McDonald, forthcoming). Most social matching systems (at least most commercial systems) support dating and romance rather than general interaction, but the techniques and issues are largely the same (Terveen and McDonald, forthcoming). The LoveGety device (Reuters/Wired News, 1998) was an early example. When a blue (male) LoveGety and a pink (female) LoveGety are within $15 \mathrm{ft}$ of one another, they beep and flash, telling the user that another LoveGety owner is close by. Codes such as "talk", "karaoke", and "get2" are used to communicate what the user is interested in. The BEDD mobile phone application available in Singapore (Straits Times, 2004) 
lets users create profiles, get matched with others within a 20 -meter radius, and then exchanges contact information for matched users. Another example is Proxy Lady, which runs on a PDA equipped with a radio transceiver (Dahlberg et al., 2000). Proxy Lady lets users associate information items (e.g. e-mails) with other people, called "candidates for interaction." When a candidate for interaction is in the proximity, Proxy Lady notifies and provides the candidate with the associated information item (e.g. the e-mail message).

Social Net infers affinities between users from patterns of co-location over time (Terry et al., 2002) resulting in it operating both synchronously and asynchronously. This is done by recording encounters between co-located users, as well as their time and duration. Periodically, these data are examined, and if a suitable pattern of co-location is observed between one user and other, the system adds information about the other user to each user's list of unknowns. This is one of two lists the system maintains, the other being a list of user-specified "friends". Social Net uses the friends list to look for a mutual acquaintance to introduce two people with a potential affinity who are unknown to each other. Every time two "friends" meet, their devices exchange lists of unknowns. If A and B belong to "unknown" lists of each other but have a common friend $\mathrm{C}$, then $\mathrm{C}$ will be prompted to introduce $\mathrm{A}$ to $\mathrm{B}$.

\subsection{PEOPLE-CENTERED: PROXIMITY: ASYNCHRONOUS}

Often proximity-based techniques combine synchronous information exchange and asynchronous processing. Social Net is one such system. Another is Hocman, a mobile peer-to-peer application that supports social interaction between motorcyclists (Esbjörnsson et al., 2003). Hocman users create HTML pages with personal information about themselves and their bikes, which are exchanged with other Hocman bikers they encounter. Hocman also offers asynchronous services, in particular the ability to browse the exchanged pages at one's leisure. Similarly, RoamWare (Wiberg, 2001) uses proximity to semi-automatically detect ad-hoc meetings and supports synchronous note taking for these meetings. After the fact, meeting notes can be shared asynchronously using a suite of CMC tools available for users' desktop computers. FolkMusic (Wiberg, 2004) uses proximity to trigger music sharing services between co-located individuals. The "Jabberwocky" devices of the "Familiar Stranger" project (Paulos and Goodman, 2004) exchange IDs when users are nearby; this data is processed to make apparent to users previously hidden information such as how many "familiar strangers" are around or how familiar a place is (based on previous presence of "familiar strangers"). 
No existing proximity-based systems that we know of rely solely on asynchronous techniques. As just discussed, some combine synchronous information exchange with various types of asynchronous processing and services. However, there certainly are opportunities to design systems that rely more on asynchronous processing. One direction is to construct systems that focus on asynchronous (rather than synchronous) use of a shared physical space. An extension is the use of geotemporal histories for social matching. People could be matched based on taking similar routes to work, for example, even if they traveled these routes at different times. These discovered affinities could be presented to users either when they were colocated synchronously or in an online space. Tradeoffs here involve potential for richer interaction vs. privacy and security concerns. We expand on these issues later.

Having completed our survey of the four types of people-centered system techniques, we now move on to place-centered techniques. Recall that they shift the focus from "users" to "locations", by associating virtual spaces with a location to represent relevant information such as current and past users, their activities and interactions. Place-centered system techniques also are divided into four sub-categories, which we consider in turn below.

\subsection{PLACE-CENTERED: USE OF PHYSICAL SPACE: SYNCHRONOUS}

The first technique builds virtual spaces that represent information about the current or past use of an associated physical space. It is only the recent development of location technology that enables this technique, so there is less existing work, and our review of this approach will be fairly brief.

Some systems provide visualizations of the current use of defined locations and areas. ActiveMap lets users visualize the location and movement of others within a workplace environment, providing large-scale, real-time awareness (McCarthy and Meidel, 1999). The application shows a map of the physical layout of the workplace. Superimposed over the map are images of the faces of employees in the locations in which they were last observed. The ActiveCampus Explorer Map overlays campus maps with avatars showing the location of a user's buddies (Griswold et al., 2003). The ActiveBadge system provides a similar feature (the LOOK command) that shows the user currently in a specified location. And a number of operators of Wi-Fi networks provide visualizations of the physical location of users connected to their network, although these users typically are anonymous. CMUSky is one example (http://www.cmusky.org/map_usercentered.html) that shows usage of CMU's Wireless Andrew System. 


\subsection{PLACE-CENTERED: USE OF PHYSICAL SPACE: ASYNCHRONOUS}

It is also possible to visualize the history of use of a physical space. Online calendars providing information about the usage of a room do this. Using location technology, such systems can be extended to include a mechanism for noting attendance in a physical space and making the data available in a persistent format. This is similar to the people-centered asynchronous system technique; however, here the focus is on a defined physical place rather than a defined set of people (say, one's buddies). The designers of FolkMusic (Wiberg, 2004) intend to use GPS receivers to map audio traces left by individuals to geographic locations, resulting in music files being associated with specific locations. The result will be a labeling of a physical space by the musical preferences of people who use the space in question.

\subsection{PLACE-CENTERED: MATCHING VIRTUAL SPACE: SYNCHRONOUS}

Synchronous online interaction spaces used by community networks and digital cities are of this type.

Community networks aim to support interaction among geographical neighbors (Schuler, 1994). Examples range from simple email lists for residents of a small township to more complex community network systems. MOOsburg is an example of a community network system for Blacksburg, Virginia (Carroll and Rosson, 2003) that provides a variety of tools including an interactive map that can be panned or zoomed to locate and navigate to virtual representations of geographical places, a related chat area, and a location-linked web board.

Digital cities integrate urban information and create public online spaces for people living or visiting those cities. For example, America Online's Digital City, Inc. service (http://digitalcity.com) provides online interaction spaces for local chat and personals in addition to standardized locationrelevant content such as restaurants, amusement parks, airport information, and shopping. 'Digital city 2' projects in Europe and Japan use high-fidelity, Internet-based simulacra of cities, updated continuously via cameras and other sensors to provide data (Ishida, 2002). Digital City Kyoto, like many digital city projects, addresses a wide range of goals spanning technology development, new information services and applications, and support for community life (Ishida, 2002; http://www.digitalcity.gr.jp/; Aurigi, 2000).

Immersive online environments increase the fidelity of the representation of physical geography by allowing interactions to be associated with specific areas of cartographic visualizations. Wireless network coverage also increases geographic specificity of interaction by both enabling and limiting the geographic area in which a set of online interactions can occur. For example, 
Wi-Fi (802.11) access points can offer community chat (e.g. Michigan wireless AP chat) that is limited to the geographic range of the access points in question. Interactions can be tied to a place through visualizations of the people using the space. The ActiveCampus Explorer system does this by allowing nearby buddies displayed on a community map to be messaged (Griswold et al., 2003). This technique is Place-Centered rather than PeopleCentered because the interaction space is not created by inter-personal proximity; rather it is situated within an online map representing a physical area, i.e., the campus.

\subsection{PLACE-CENTERED: MATCHING VIRTUAL SPACE: ASYNCHRONOUS}

This is probably the most common type of online interaction space used by community networks and digital cities. Standard asynchronous communication tools such as email lists and web boards are used to support interaction for or about a particular physical location. Some interesting system designs developed outside of community networks and digital cities include: (1) spatially (latitude/longitude) addressable web based bulletin boards that enforce the geocoding of messages (e.g. IBM's World Board, Spohrer, 1999); (2) "community geoblogs" (http://www.brainoff.com/geoblog/); and (3) digital graffiti systems that allow digital messages to be linked to physical locations. These digital notes behave like electronic Post-its, visible to authorized users on their mobile devices when they enter the vicinity (Brown, 1995) or remotely (Burrell and Gay, 2001). Systems that allow these messages to be read remotely index the messages by locations. These can then be searched or accessed by navigating online maps. Example systems include E-Graffiti (Burrell and Gay, 2001), Geonotes (Espinoza et al., 2001), and the "graffiti" function of the $A c$ tive Campus Explorer (Griswold et al., 2003).

\subsection{P3-SYSTEMS FRAMEWORK SUMMARY}

The P3-System framework outlined in this Section helps us describe the design space for place-sensitive community systems by distinguishing between eight basic techniques to providing location contextualized information. Table II graphically summarizes the framework by placing a small number of representative systems and techniques in each of the eight cells of the framework. It hints at the possibility, to be examined further below, that each of the different P3-System approaches is likely to support different types of tasks, such as maintaining of awareness of the location of buddies or the navigation of places. A consequence of these differences is a need for different types of interface designs, and different associated concerns in regards to privacy. We will examine these claims in greater detail in the next two sections. 
Table II. Representative P3-Systems and techniques

\begin{tabular}{|c|c|c|c|}
\hline $\begin{array}{c}\text { P3-system design } \\
\text { approaches }\end{array}$ & & $\begin{array}{l}\text { Synchronous } \\
\text { communication or } \\
\text { synchronous location } \\
\text { awareness }\end{array}$ & $\begin{array}{l}\text { Asynchronous } \\
\text { communication or } \\
\text { asynchronous location } \\
\text { awareness }\end{array}$ \\
\hline \multirow[t]{2}{*}{ People-Centered } & $\begin{array}{l}\text { Absolute } \\
\text { user } \\
\text { location }\end{array}$ & $\begin{array}{l}\text { Active Badge - } \\
\text { FIND Lemming - } \\
\text { IM buddy } \\
\text { location labels }\end{array}$ & $\begin{array}{l}\text { Ulocate - location } \\
\text { history }\end{array}$ \\
\hline & $\begin{array}{l}\text { Co-location/ } \\
\text { proximity }\end{array}$ & $\begin{array}{l}\text { LoveGety - } \\
\text { Match Alerts Social } \\
\text { Net - potential new } \\
\text { co-located friend alert }\end{array}$ & $\begin{array}{l}\text { Hocman- webboard } \\
\text { supported by motorcy- } \\
\text { clist co-location history }\end{array}$ \\
\hline \multirow[t]{2}{*}{ Place-Centered } & $\begin{array}{l}\text { Use of physical } \\
\text { places by people }\end{array}$ & $\begin{array}{l}\text { ActiveBadge - } \\
\text { LOOK ActiveCampus } \\
\text { maps CMUSky }\end{array}$ & $\begin{array}{l}\text { FolkMusic (Location- } \\
\text { based music history) on- } \\
\text { line room calendars }\end{array}$ \\
\hline & $\begin{array}{l}\text { Use of matching } \\
\text { virtual places }\end{array}$ & $\begin{array}{l}\text { Wi-Fi AP Chat digital } \\
\text { cities and community } \\
\text { network chat }\end{array}$ & $\begin{array}{l}\text { GeoNotes, ActiveCam- } \\
\text { pus graffiti }\end{array}$ \\
\hline
\end{tabular}

\section{Tasks}

The aim of this section is to demonstrate the utility of the framework by showing how various P3-System user tasks can be derived from it. More specifically, we will map particular tasks to cells in Table III. Following the framework, we identify two main classes of task, people-centered and placecentered. These include many core CSCW tasks (albeit cast in the context of P3-Systems) such as awareness and informal communication, coordination, social matching, and social navigation. People-centered tasks include meeting, communicating with, or tracking other people, and utilize place information to achieve these essentially social goals. Place-centered tasks flip the perspective, focusing on navigation within and decision-making relative to a place and associated activities, with social information serving as a resource for these tasks.

Table III summarizes relationship between techniques and tasks; for each technique, we list one or two important tasks and briefly characterize the form they take here. The rest of this section elaborates on these relationships. (For ease of exposition, we label the different techniques from 1 to 8). 
Table III. P3-Systems framework and representative tasks

\begin{tabular}{|c|c|c|c|}
\hline \multicolumn{2}{|c|}{$\begin{array}{l}\text { P3-System design } \\
\text { approaches }\end{array}$} & $\begin{array}{l}\text { Synchronous communication or } \\
\text { synchronous location } \\
\text { awareness }\end{array}$ & $\begin{array}{l}\text { Asynchronous } \\
\text { communication or asyn- } \\
\text { chronous location aware- } \\
\text { ness }\end{array}$ \\
\hline \multirow[t]{2}{*}{$\begin{array}{l}\text { People- } \\
\text { Centered }\end{array}$} & $\begin{array}{l}\text { Absolute user } \\
\text { location }\end{array}$ & $\begin{array}{l}\text { 1. Utilizes current location of } \\
\text { particular users. } \\
\text { - Informal communication } \\
\text { with buddies: Where is } \mathrm{X} \\
\text { now? Is Y running late, } \\
\text { and when will she arrive? } \\
\text { - Security: Where is } \mathrm{Z} \text { now? }\end{array}$ & $\begin{array}{l}\text { 2. Utilizes particular peo- } \\
\text { ple's location histories. } \\
\text { - Coordinating/scheduling } \\
\text { (via analysis of history): } \\
\text { When is X usually around? } \\
\text { - Security: Where has Y } \\
\text { been? }\end{array}$ \\
\hline & $\begin{array}{l}\text { Co-location/ } \\
\text { proximity }\end{array}$ & $\begin{array}{l}\text { 3. Utilizes real-time user } \\
\text { co-location. } \\
\text { - Social matching: Who is } \\
\text { close to me now? Is there } \\
\text { anybody around whom I'd } \\
\text { like to meet? } \\
\text { - Security: Who is nearby? }\end{array}$ & $\begin{array}{l}\text { 4. Utilizes co-location his- } \\
\text { tory. } \\
\text { - Social matching: Who } \\
\text { has geo-temporal routines } \\
\text { like me? } \\
\text { - Social accounting: How } \\
\text { much time did I spend } \\
\text { with X? When did I last } \\
\text { meet X? }\end{array}$ \\
\hline $\begin{array}{l}\text { Place- } \\
\text { Centered }\end{array}$ & $\begin{array}{l}\text { Use of physical } \\
\text { places by people }\end{array}$ & $\begin{array}{l}\text { 5. Utilizes online representation } \\
\text { of user's current use } \\
\text { of physical spaces. } \\
\text { - Task coordination: Is anyone } \\
\text { in this place now that might help } \\
\text { with a place-based task, } \\
\text { e.g., get me a coffee, pick up } \\
\text { a printout, or reboot a machine? } \\
\text { - Social navigation: How busy } \\
\text { is this place now? } \\
\text { Who is in this place now? } \\
\text { What music is playing } \\
\text { there now? } \\
\text { How fast is traffic moving } \\
\text { on various routes? }\end{array}$ & $\begin{array}{l}\text { 6. Utilizes history of peo- } \\
\text { ple's use of a particular } \\
\text { space. } \\
\text { - Task coordination: Does } \\
\text { anyone I know go to this } \\
\text { place, so I might request } \\
\text { them to do an errand for } \\
\text { me? } \\
\text { - Social navigation: Does } \\
\text { this place tend to be busy } \\
\text { at specific times. Who } \\
\text { tends to go to this place? } \\
\text { Do people like me use this } \\
\text { place? What music is typi- } \\
\text { cally listened to here? }\end{array}$ \\
\hline
\end{tabular}


Table III. (Continued).

\begin{tabular}{|c|c|c|}
\hline $\begin{array}{l}\text { P3-System design } \\
\text { approaches }\end{array}$ & $\begin{array}{l}\text { Synchronous communication or } \\
\text { synchronous location } \\
\text { awareness }\end{array}$ & $\begin{array}{l}\text { Asynchronous } \\
\text { communication or asyn- } \\
\text { chronous location aware- } \\
\text { ness }\end{array}$ \\
\hline $\begin{array}{l}\text { Use of } \\
\text { matching } \\
\text { virtual places }\end{array}$ & $\begin{array}{l}\text { 7. Utilizes synchronous online } \\
\text { spaces related to physical } \\
\text { location. } \\
\text { - Communication: What are } \\
\text { people saying about this place } \\
\text { now? } \\
\text { - Social navigation: How do } \\
\text { people describe the activities } \\
\text { happening here now? }\end{array}$ & $\begin{array}{l}\text { 8. Utilizes asynchronous } \\
\text { online spaces related to } \\
\text { physical location. } \\
\text { - Communication: Leave } \\
\text { notices about upcoming } \\
\text { events, e.g., that person X } \\
\text { is giving a talk next week. } \\
\text { - Social navigation: What } \\
\text { have people said about } \\
\text { activities that occur here } \\
\text { or services that are offered } \\
\text { here? }\end{array}$ \\
\hline
\end{tabular}

\subsection{PEOPLE-CENTERED TASKS}

People-Centered tasks (cells 1-4 of Table III) put people at the center. People-Centered P3-System techniques facilitate these tasks by providing information about location of or proximity between users; in other words, these are People-To-People tasks, with Place used as resource. This information enables enhanced forms of awareness and several types of asynchronous processing that aid users in opportunistic communication or coordination with people they already know, meeting new people, managing interpersonal relationships, and maintaining security.

\section{Opportunistic Communications with Friends and Colleagues}

Informal, opportunistic communication is common - and critical - both for effective work (Kraut and Streeter, 1995; Oslon and Olson, 2000; Isaacs et al., 2002) and for maintenance of social relationships (Nardi et al., 2000; Whittaker et al., 2002). However, over time as people's lives have become busier, work practices have shifted, schedules have become more flexible and informal communication has suffered.

P3-Systems that use location information - absolute or proximity-based can help. Consider several examples:

- (Cell 1) A system that tells you when your colleagues are at work - whether a place-enhanced IM system or a simple notification system - would both remind you of their presence and enable you to drop by their offices. 
- (Cell 3) A system that tells you where you are close to your colleagues would have similar effects; this might be most useful on large, spread-out corporate campuses. And knowing that your friends were close to you when you were out on the town or at the mall would give you the chance for enhanced social interaction.

We also note that location information can be used to avoid opportunistic communication. In a recent empirical study (Jones et al., 2004), we found that several people reported wanting to know the location of other members of their work team in order to avoid running into them.

\section{Coordination with Colleagues}

Flexible work schedules also have made it harder for people to arrange meetings. Technologies such as online calendars and IM help in such situations. Systems that asynchronously process location history can help even more (cell 2). For example, a system by Begole et al. (2002) inferred regularities in people's work routines (based in part on analysis of their history of being in the office), e.g., when they were and were not likely to be in the office. This enables coordination strategies of the form "let's schedule the meeting for late afternoon, because that's when Tom and Felicia are most likely to be around" or "how about we talk tomorrow morning over coffee at the Espresso Royale?" Note that synchronous location information (cell 1) also can help in coordinating meetings, e.g. by providing information that one of the participants is running late.

\section{Social Matching}

The previous tasks involved enhanced communication and coordination among people who already know each other. However, location information - specifically proximity information - also is a powerful resource for meeting new people. We already have discussed how systems like LoveGety, ProxyLady, Social Net, and BEDD supported such social matching, whether by simply matching profiles among people who are close to each other (cell 3) or discovering patterns of co-location over time to infer affinities (cell 4).

Note that meeting a new person is inherently risky (raising the possibility of at least social awkwardness and perhaps even danger). One way around this is to arrange for the "introduction" process and initial interaction to occur online, with face-to-face interaction happening only when sufficient comfort and trust is achieved. Another approach would be for a system to recommend places to meet, based on both the matched party's routines (i.e., to find places they both frequent) and the properties of the place (e.g., that they are public, in safe areas, etc.). This is rather like a personalized Meetup.com that suggests where the meetup should occur. 


\section{Assuring Security}

The last example raised the important issue of maintaining security and safety for oneself and others. One specific application is to track those, such as children or the elderly or cognitively impaired, who may be unable to keep themselves safe (cell 1). For this type of tracking system - at least under normal circumstances - awareness alone is the main function, rather than awareness as an enabler of information communication. That is, observers need to communicate with the tracked person only when an emergency arises.

P3-Systems also can help people assure their own security, e.g., by finding nearby acquaintances to walk with to a parking lot late at night (cell 3). The Familiar Stranger project (Paulos and Goodman, 2004) explored ways to let people assess the nature of a place through the presence of others whom one has been together with in other circumstances (cell 4).

\section{Social Accounting for Relationship Management}

People expend effort tending to their personal and professional relationships, for example, by contacting colleagues at regular intervals, keeping track of personal details like birthdays and anniversaries, etc. P3-Systems can aid in this process by storing and analyzing co-location history to answer questions such as "how much time have I spent with Syd in the last month?" (cell 4). And by combining this with absolute location, a system can also remind you where and when you've met someone.

\subsection{PLACE-CENTERED TASKS}

Place-Centered tasks shift the focus to making decisions about and acting in specific locations. Social information is used as a resource for these tasks; in other words, these are People-to-Place tasks, with (information from and about other) people used as a resource.

\section{Social Navigation}

One often needs information about places and associated activities to make some decision (cells 5-8), even if it is as basic as deciding which place to go to. Even simple information such as how many people currently occupy a place is useful (cell 5). For example, you might decide to go to a restaurant that isn't busy to avoid a wait. On the other hand, you might prefer to visit a club or pub that is busy because this suggests it's a current cultural hotspot. And systems that analyze place usage logs (cell 6) can provide additional guidance, such as determining a good time to schedule an outing to a park, or telling you something about the ambience of a place, such as the type of music that typically is played there. 
Information related to activities in a place also can be found by examining digital comments, such as ratings and reviews (cells 7 and 8). Such information is useful not just to people deciding whether to visit a place or engage in an activity, but to the place "owner" - for example, a shopkeeper - who wants to understand the users and improve their experience.

Of course, social navigation of online "places" also can be done with analogous types of information; indeed, this is where the metaphor of social navigation originated.

\section{Task Coordination}

Some tasks can only be carried out in particular places, e.g., getting a cup of coffee from the local coffee shop, or picking up a newspaper from a newsstand, or putting up a notice in the foyer. If someone isn't currently at the appropriate place, they may ask someone else who is - e.g., a friend or colleague - to do the task for them. Since these tasks relate to a place, the relevant part of the framework is cell 5 - a user would focus on the place, and then look for buddies who currently are there or nearby.

As we've seen before, systems that analyze history data (cell 6) allow for advance planning, enabling requests like "if you wouldn't mind stopping by the student union on your way in from the parking garage, would you please pick up a course catalog for me?

\section{Communication about Places and Activities}

In addition to judging a place based on current or typical usage of that place (cells 5 and 6), people often want to share opinions and communicate about a place (cells 7 and 8). For example, people may want talk to those who are responsible for a place or who are regular users.

\subsection{DISCUSSION}

We have illustrated how key user tasks are manifested in different aspects of the P3 framework. We touch on a few additional issues here. First, note that different P3 techniques can be used to support the same task. This is particularly true when information about people and place coincides. For example, I might locate person $\mathrm{X}$ by visualizing the cafeteria (cell 5) rather than by tracking X's movements (cell 1). Or I might try to meet new people who hang out in the virtual place associated with my favorite music club (cell 7), rather than relying on a system to discover our affinity through analysis of co-location patterns (cell 4). This is analogous to computer-mediated communication tools such as email, instant messaging, or discussion boards; each has its particular strengths and prototypical uses, yet there is overlap in the tasks they support. 
Second, we have not analyzed in any detail the fact that not all relationships are equivalent. "Buddies" have different status and importance, and this may influence the way that certain tasks are carried out. For example, there may be certain buddies with whom you absolutely must communicate frequently; or there may be others where the relationship is not strong enough to ask them to carry out a task for you.

Finally, the task taxonomy has important implications for user interface design. For example, knowing that social navigation is largely a place-centered task suggests that interfaces that aim to support such tasks should be organized around a representation of a (real or virtual) place. In contrast, people-centered tasks like information communication and coordination require people to be the central organizing principle for the interface, e.g., as in the buddy list of an Instant Messenger.

\section{Privacy}

As we have seen, P3-Systems require users to disclose personal information, notably their locations and opinions about various places and place-based activities. Therefore, the issue of maintaining one's privacy is crucial. More precisely, users must be able to assess the implications of revealing personal information and decide that the benefits this yields justify the potential for abuse. We should note that any system that requires users to provide personal data raises many privacy concerns such as security of communications and data storage and the trustworthiness of system owners. Moreover, many papers have explored privacy issues in collaborative computing systems, raising themes such as: the importance of context in an "openness-closedness" spectrum of privacy (Palen and Dourish, 2003); the need for legal rules in information handling practices (Westin, 1967; Langheinrich, 2001); and the importance of effective communication to users about data collection and handling practices (Langheinrich, 2002).

Since others are addressing these issues, we don't discuss them in any more detail here. Further, even when these issues are solved, P3 systems raise distinct privacy issues, so it is these that we must address. We review the privacy issues raised by the different P3-System techniques; it is notable that the framework makes it clear that different techniques raise different issues. We also show how different factors of a P3-System's context can influence

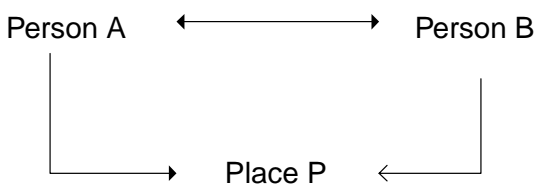

Figure 1. Contextual factors of a P3-System. 
privacy requirements and inform the design of privacy management policies and tools.

\subsection{CONTEXTUAL FACTORS OF A P3-SYSTEM}

Consider a generic P3-System: for simplicity of exposition, Figure 1 illustrates an interaction between two people in the context of place.

The context of the system consists of the following factors:

- Attributes/properties of the people (individual uses), including general attitudes and interests and current disposition.

- Properties of the place, e.g., place-type (e.g., restaurant, classroom, etc.), who frequents the location in question, social norms concerning expected behaviors of people in the place, etc.

- The relationship between the people, including whether they already know each other, whether they have mutual acquaintances, whether they belong to the same organization, etc.

- The relationship between the people and the place, including things such as whether they have a distinct role (a student vs. a teacher in a classroom, a customer vs. a waiter in a restaurant) and their familiarity with the place.

In the following discussion, we shall show that systematic use of these contextual factors, though development of context-aware features, could lead to improved privacy management.

\subsection{PEOPLE-CENTERED SYSTEMS: ABSOLUTE USER LOCATION}

The key issue here is that users can be tracked or "stalked", potentially violating their desire for privacy and perhaps even putting them in danger.

A simple way to avoid these problems is to turn off or stop carrying a location, sensing device. That was the options ActiveBadge users had, for example. However, turning off or taking off a badge had social consequences: it was a noticeable act that other users could question. Because of these and other social issues, the organization in which ActiveBadge was originally deployed could not develop social conventions for badge use and split into hostile camps of badge wearers and badge skeptics (Harper, 1992).

A second way to address privacy concerns is to limit the storage of location history information. The ActiveBadge systems stored only the last hour of data (Want et al., 1992). While this might limit abuse, it also limited the possibility for the interesting types of asynchronous analysis we have discussed. It would be harder to identify common patterns in different people's geotemporal routines. And even simple types of information useful for coordination - "Was Stanley in the office yesterday?" or "When did Francis last visit the Envision team?" - would be lost. 
Some systems explicitly reserve for users the decision to disclose their location information. Hong and Landay (2004) describe a location-enhanced Instant Messaging system. When a buddy queries a user's location, users were notified of the request. Users could then choose to disclose their location "just this once" or state a rule defining circumstances under which the request should be granted, e.g., only to this requestor between 9am and 5pm Monday through Friday. Once rules have been defined, the system checks incoming requests to see if they are covered by the rules before notifying the user. The ActiveCampus Explorer (Griswold et al., 2003) also allows users to adjust when they are seen by others using various rules. One such rule is reciprocity ("I will let you see my location if you let me see your location").

While these approaches have their place, they don't solve all problems. For example, they may leave little room for "plausible deniability" ("Oh, sorry, I guess I was out of range"), a key to avoiding embarrassing situations, unwanted interruptions, and tedious social obligations. Further, in active P3System environments, the Hong and Landay approach faces a dilemma. If users handle all requests manually, they might be interrupted too frequently; on the other hand, it is unclear whether people can anticipate the consequences of rules, and rules are inherently inflexible.

\section{P3 Support}

We believe that the contextual factors we identified above can help systems alleviate these problems. Systems can use the factors in two ways: (1) by making them explicit in user interfaces, and (2) by using them to make decisions automatically. For example, access rules often can be set based on the relationship between users and a potential viewer of their information. Parents typically have rights to view information about their children, and employers may be able to track their employees when they are driving company vehicles during business hours. Additionally, there are many ways in which the relationship of people to a place is useful, including: Sara might be willing to let her colleagues know that she is on the way to work; students might let friends view their location while they are on campus. Further, these rules can be used to enforce social norms. For example, a system could enforce a rule such as campus security can view remotely the identity of individuals in laboratories around campus.

\subsection{PEOPLE-CENTERED SYSTEMS: PROXIMITY}

One key task that this class of systems serves is social matching. Important challenges include letting users retain control the matching process and making effective introductions between matched users without disclosing any more information than is required. 
The first problem arises in systems that do synchronous matching based on user profiles. Does a young woman waiting for a train want to take the chance of being inundated with notifications? Does she want to have to look around to figure out which of the nearby men is "Zeke57" or "DeputyAndy"? Will she be disclosing her identity as soon as she looks around?

Other issues arise when asynchronous processing is added to the mix. Consider a system deployed within an organization that records when people are in proximity. It could analyze these data to identify ad-hoc work groups; this information might be useful for organizational planning and the allocation of resources. However, the same data and the same type of analysis might inappropriately reveal a budding office romance.

To avoid such problems, the Social Net system did not reveal any information to users about their patterns of co-location - in fact, the system doesn't even know where the users were co-located, or whether they have met in different locations or just one. The designers acknowledged that this causes problems in introducing matched users. Specifically, there is no way to tell users what it is that the system thinks they have in common. Thus, there is a tradeoff between how effectively matched users can be introduced and the amount of personal information that must be disclosed.

\section{P3 Support}

To illustrate how contextual factors can lead to an effective interaction that still preserves user privacy, consider the following scenario.

One afternoon, Nicole is relaxing at the university cafeteria when her MatchMe device vibrates to indicate she has a message. She sees that it has detected another academic in the vicinity that she might wish to meet, who is male and in his 30s. Though his identity is not revealed, Nicole is informed that they have several friends in common. Nicole is typically hesitant about meeting strangers. However, in this case she sends a message that she is willing to meet.

She does this because she knows that Bruce did not initiate the request, rather a trusted computer system would implicitly "vouch for" Bruce, because they share some common interests and common friends and further because she is in a trusted secure 'place'.

First, the properties of the place - a relaxed social setting where conversation and noise are accepted - made it acceptable to deliver a notification where Nicole is likely to respond. Second, the fact that Nicole has some common friends with the stranger serves to both vouch for him and increase their common ground. 


\subsection{PLACE-CENTERED: USE OF PHYSICAL SPACE}

Place-centered systems do not raise as many privacy concerns as peoplecentered systems do. Anonymous location data often is useful: just knowing that a restaurant or theater is crowded is useful, even without revealing who is there. Of course, sometimes it is useful to know the identity of people in a place: when this is desired, the concerns we considered for people-centered systems again arise. However, there is a way in which these concerns may be addressed more easily: places usually have "owners", as well as fairly clear social norms that include privacy expectations. While a friend can just walk over and talk to you if you're at a coffeeshop, s/he would knock on your door before coming into your office, and would most likely call ahead or even arrange a time before coming over to your house.

There are exceptions to the usual norms about privacy. For example, while I certainly have the right to know who's in my home, my wife may be throwing me a surprise birthday party, and may want to hide from me the fact that the house is filling up with friends and family.

Finally, note that certain system functionalities could push place-centered systems more toward people-centered systems. If a system lets me search across and within places for particular people, then it becomes a de-facto person-centered system, and thus faces the more acute privacy concerns of that class of systems.

\section{P3 Support}

One relevant factor is the relationship between a person in a place and others who might seek awareness of who's in that place. For example, it may be acceptable for a foreman to see the precise details of who is currently at a particular work site. People's relation to a place also is useful. For example, students might be willing to share their location on campus with fellow students, but not with visitors to the campus or even their family members. Similarly, a lab monitor, by virtue of his/her role in a lab, may be allowed to remotely monitor who is in the lab during work hours.

\subsection{PLACE-CENTERED: MATCHING VIRTUAL SPACES}

Since this class of systems involves interaction in a virtual space (that is associated with a physical place), all the privacy issues of virtual spaces are relevant here. P3-System specific privacy issues arise if messages posted are tagged with the author's location or if someone wishing to write a message must be present at the relevant place to post it. 
One important emerging issue is data ownership. The controversy over the "Third Voice" web service shows the importance and difficulty of these issues (http://www.wired.com/news/business/0,1367,42803,00.html). For P3Systems, questions that these issues raise include: Do the owners of a physical places have any legal rights over matching virtual spaces?; Suppose the matching virtual space can be used only in or near the place (e.g., if every Starbucks had its own IRC chat channel accessible only through its WiFi hotspot) - should that give the owners of the physical place extra rights over the virtual space? There certainly are circumstances where ownership of a physical place suggests special control over the virtual space. For example, a theater may wish to ensure that the display of audience messages is sorted by performance dates, a church may wish to ensure that language in its online space is in keeping with the place of worship, and an office work may want to be able to moderate digital graffiti postings associated with his/her office. More generally, user rights in a virtual space could be based on their relationship to the physical space. For example, faculty at a university may be able to see different digital graffiti in a classroom than the students.

\section{P3 Support}

Since user participation in virtual spaces can be anonymous and voluntary, with well-defined access rights to others, privacy issues here are not as difficult as for other P3-System techniques.

\subsection{SUMMARY: PRIVACY AND P3-SYSTEMS}

Privacy concerns have been a major obstacle to the deployment of P3-Systems. For example, most systems have been synchronous, in part due to concerns over the privacy implications of making ephemeral movements in space leave a persistent record (as stated by the designers of ActiveBadge Want et al., 1992; and Social Net - Terry et al., 2002). However, our discussion has shown that asynchronous processing enables new and potentially useful applications.

Clearly, many privacy concerns can only be addressed by general improvements in computer system security and trust. Nevertheless, we have shown that there are major privacy concerns distinct to P3-Systems. We also have shown the systems that exploit relevant contextual factors - properties of people and places, and relationships between them - have the potential to address these concerns.

Ultimately, as Lessig (1998) argued, privacy must be ensured through a combination of technology, legislation, corporate policy, and social norms. Our proposal urges that technological management of privacy be more integrated with social norms. It does so by arguing that privacy management tools should incorporate factors of place and social relationships. 
We further observe that people have a range of attitudes towards disclosing personal data (Nodder, 2003) and that there are different ways to conceptualize the issues. Privacy analysis in CSCW has tended "to look at privacy from the perspective of individual end-users and their relationships, rather than that of large communities" (Hong and Landay, 2004, p. 178). However, particular communities may mandate privacy or openness policies that do not necessarily match particular individuals' needs or desires (Etzioni, 1999). An example of mandated openness in a community is the enforced display of license plates on cars (Hong and Landay, 2004), and an example of mandated privacy is the "moral laws" limiting the public consumption of alcohol (Etzioni, 1999, p. 196). P3-System privacy management tools could likewise incorporate certain access rules mandated by the community.

We conclude this section with a hypothetical scenario that summarizes the ideas by describing the movements of Brad, a university student, over the course of two typical days.

On Sunday, Brad wakes up at his parents' home and spends most of the day there. The rules here specify that family members can see (remotely) who is at home but nobody else can. By default, Brad's rules for disclosing his location outside of his work and study hours are that a small group of friends can know what neighborhood he is in. When he steps out to the local supermarket, the proximity matching rules of the supermarket place-type result in his mobile phone alerting him that an unidentified friend is nearby, and gives him the option of revealing his identity. He does, and ends up talking briefly to an old high school friend, who is home for the weekend from an out of state college. On Monday morning, Brad heads for the university; unfortunately, having overslept and he's going to be a bit late for a scheduled meeting with a professor and two other students. Luckily, though, because of their relationship to him and to a shared place (their research group's lab space), they receive a notification that Brad's travel path suggests he will be late by 15 minutes. Once Brad reaches campus, the campus rules take effect, making the fact that he is on campus available to other university students, faculty and staff. The same campus rules make his exact location on campus available to his "university friends" and the professor he has a meeting with, while keeping him invisible to any other users who are not directly connected to student activities on campus.

\section{Discussion}

Until recently, information systems that systematically link people-to-peopleto-geographic-place have not been considered as a related or distinct category. However, recognizing P3-Systems as a distinct class of applications lets us distinguish between basic design features and provides a conceptual 
framework for future development in this area. The past few sections have shown the utility of the P3-Systems framework for organizing the design space for an emerging class of systems, showing how important CSCW tasks can be supported, and suggesting ways in which key privacy issues can be addressed. To realize this potential, however, difficult socio-technical challenges must be addressed, including: (1) conceptual issues concerning notions of place, community, and identity; (2) algorithms for place discovery and labeling, social matching, and place-based recommendation; and (3) interaction techniques for managing complex people-centered and place-centered information on a variety of devices.

\subsection{CONCEPTUAL ISSUES}

Our framework relates people to place; as such, realizing its implications forces us to three conceptual issues, one concerning place, and two concerning people, specifically community and individual identity.

Research from environmental psychology and architecture shows that places (such as schools, offices, or theaters) shape behavior; however, many questions remain unanswered, particularly from a system design perspective. For example: At what level do people carve the world up into places? How do people describe places, and to what extent does a description used by one person make sense to others? Under what circumstances do people want to know about other people in a place? And when are people willing to share information about their presence in a place? We have begun empirical investigations of these questions (Jones et al., 2004).

New technologies have changed conceptions of community. So-called "online communities" showed that interpersonal relationships and social networks could be constructed independent of a geographic nexus and faceto-face contact. Artificial social network tools, such as Friendster and Orkut, showed that people are eager to enumerate and publicize their social relationships, with little regard to privacy or concern for nuances of relationships, and without clear functional benefits. We expect the "re-placing" of community to raise other questions, such as: How can communities integrate participants who do and do not share a geographical location? How do such "mixed-reality" communities co-exist with non members within the same geographical locale? Do community members desire the enforcement of different access rights to members based on their semantic and physical relationship to the community? To what extent can such rights be enforced?

Online communities have raised to prominence many issues of identity such as differential presentations of self to different audiences. Users can be anonymous or pseudonymous; they can represent themselves with textually described or graphically presented avatars; they can enact roles or assume 
false identities (e.g., Turkle, 1995). Once interaction is re-embedded in physical space, however, such possibilities are constrained. We see this already when online interaction is intended to lead to face-to-face interaction, e.g., as in dating systems; stories of people who present themselves as younger and more attractive than they really are and thus disappoint their partner have become a cliché. Therefore, P3-Systems face questions such as: How can users retain some flexibility in their self presentations? How can systems allow anonymity while maintaining accountability?

\subsection{ALGORITHMS}

To realize our vision of P3-Systems that support users in key tasks, more sophisticated algorithms will have to be developed. These fall into three main categories: algorithms for discovering, labeling and expressive representations of "place"; algorithms for suggesting new social relationships; and algorithms for combining social and location information to recommend places and activities.

Place Discovery, Labeling, and Representation - Many P3-Systems need to represent places and obtain descriptions of them (such as "the NJIT Stadium", " HCI group coffee area") and identify when a user is "at" a place. A simple, but important example is a place-enhanced Instant Messenger that could show you that (for example) your buddy Tom is in the "CoSpace Lab". There have been algorithms for defining places and obtaining labels (Marmasse and Schmandt, 2000; Ashbrook and Starner, 2002; Hightower, 2003). However, none of them have been empirically verified; indeed, the very standards for defining how to evaluate these algorithms have not been stated. Further, while there is sense among researchers that scalability requires algorithms to be interactive and place descriptions to be shared among users, these assumptions have not been tested either. We currently are engaged in work that addresses these issues by: the invention of an improved algorithm, the definition of a clear evaluation procedure, and a large-scale empirical evaluation study.

Further, we need sufficiently expressive representations of places, combining geometric representation, e.g., in terms of points or regions (see Shekhar and Chawla, 2003, chapters 2 and 3, including the discussion of the OGIS model) and logical representations based on places, their interrelationships, and perhaps even their temporal properties. They must be able to handle places that overlap, and single geographical locations that contain multiple places. For example, a room might be used as a class room during the day and dance floor in the evening.

Algorithms for aiding users in social navigation tasks must also be able to utilize relational and dynamic properties of places. For example: What does 
it mean for a place to be crowded? When is a place typically crowded? What are the good times to meet new people in this place? It must also be able to achieve equivalent goals for online matching spaces (4th row of the frame work): When is discourse typically active? When is it occupied by particular types of people? When are the interactions overloaded (Jones et al., 2004).

Social matching - As we have discussed, there are many ways to support users in making new acquaintances and forming new relationships. Possibilities include:

- Manual searching of user profiles in an online space.

- Online matchmaking based on user profiles, e.g., as done by dating systems such as match.com.

- Proximity-based profile matching, e.g., as done by LoveGety or BEDD.

- Matching based on similarities in geotemporal routines; Social Net does a very simple version of this.

There are opportunities to develop social matching algorithms that exploit the various P3-System techniques and even combine several techniques. For example, algorithms for matching location histories can search for common or nearby locations and similar paths, and even take time into account (e.g., it is more interesting to know that two people have been at the community soccer field at the same time than simply that they've both been there). Such algorithms will be even more effective if they use information about place types; for example, two individuals might make a good match if they both are regular churchgoers, even if they go to different churches. And as we have discussed, even when matches are computed on the basis of recurring patterns of colocation, introducing matched users to each other is more effective when the system records - and can describe - the actual places the users had in common.

Place-based recommenders. Recommender systems use knowledge of user preferences and item properties to identify items users are likely to enjoy. A place-based recommender system represents and reasons with user preferences - either inferred from use or stated explicitly - about places and associated activities. For example, a system could infer user preferences for particular types of cuisine from the restaurants they frequent in their home town and use this information to recommend restaurants when they travel. Or regular visits to an organic market could be used to recommend natural foods restaurants. And, of course, collaborative techniques could recommend restaurants frequented by people who spend time in some of the same places as a user. When virtual spaces are associated with physical places, a common use is to allow users to enter ratings and express opinions; these in turn could be utilized by place-based recommender systems.

Recommender algorithms also would profit by taking into account the current status of a place. For example, in addition to considering a restaurant's overall quality and a user's culinary tastes, the system could base its recommendations on the wait time for a table and the ambient noise level. A 
significant challenge - and opportunity - is to develop recommendation algorithms that combine these diverse types of implicit and explicit user preferences and place information.

\subsection{INTERACTION TECHNIQUES/USER INTERFACE DESIGN}

Many of the tasks that P3-Systems support require users to enter, view, and manage complex data - and, what's more, to do it on a range of devices from desktop computers to mobile phones. Thus, the invention of powerful interaction techniques and the design of effective and easy to use interfaces are key requirements. As we discussed above, the task of managing personal information privacy management is one area where these requirements clearly arise. We will not revisit this topic here; instead, we touch on issues in managing location-linked digital messages and visualizing information about places and people in a scalable way.

Letting users create a digital messages that are associated with geographical places requires the development of new interface tools (for a discussion of such interfaces, see Espinoza et al., 2003). As we noted earlier, messages can be presented through chat spaces, as digital graffiti, or simply as alerts. Often a message creator wants the message to be readable only by certain individuals or groups, such as current or frequent users of a place, members of a specific work team, or those willing to do a place-sensitive task. Thus interfaces must make it easy to specify the appropriate permissions. Another a basic design issue is how to associate a message with a place. Methods include: (1) labeling messages with a place, e.g., augmenting telephone caller ID information with the caller's location; (2) creating entire online places dedicated to a physical place; (3) using cartographic visualizations, i.e., visualizing messages at particular points on a map; and (4) limiting access to those actually in a physical place, e.g., GeoNotes requires both authors and readers of notes about a location to be in that location. The advantages and disadvantages of each of these approaches are only now starting to be explored.

How should people-centered or place-centered systems actually visualize their information? Techniques range from simple buddy lists, as seen in ActiveBadge (Want et al., 1992) and Lemming (Hong and Landay, 2004) to cartographic visualizations, as seen in ActiveCampus explorer (Griswold et al., 2003) and ActiveMaps (McCarthy and Meidal, 1999), to more abstract social proxies (Erickson, 2003). All these approaches face issues of scalability: none have been demonstrated to work except for small groups and limited geographical areas. Perhaps this is acceptable: maybe cognitive processing limits and social constraints mean that people do not need to keep track of large groups or wide areas. However, empirical studies are necessary to decide one way or the other. 
Finally, note that many P3-Systems work on small devices, typically cell phones. Thus, all the challenges of designing for devices with limited $\mathrm{I} / \mathrm{O}$ capabilities must be faced. Complex visual designs, such as interactive maps, are especially difficult to offer on such devices, which often means that designers must work hard to understand the essential aspects of user tasks and invent new techniques that do work on these devices.

\section{Summary}

We have presented the P3-framework for systems that link People-to-Peopleto-Geographical-Places and demonstrated its utility in several ways. First, we believe that simply defining the category will encourage better work by making researchers aware of related work, the range of design techniques, and representative design problems. Second, we demonstrated that the framework can categorize existing systems. Third, we showed how central CSCW tasks arise in the P3-System context, and how different P3-Systems techniques can address them. Fourth, we showed how the key CSCW and context-aware issues of privacy take different forms and different levels of importance in different types of P3-Systems and suggested types of information that systems can use to help users address the issue. Finally, we identified a set of socio-technical challenges that researchers and designers must confront to realize the potential of P3-Systems.

\section{Acknowledgements}

This material is based on work supported by the United States National Science Foundation under Grant Numbers DST 0308018 and DST 0307459. Any opinions, findings and conclusions or recommendations expressed in this material are those of the author(s) and do not necessarily reflect those of the National Science Foundation. We would also like to acknowledge support from The NJ Center for Pervasive Information Technology, funded by the New Jersey Commission on Science and Technology.

\section{Note}

${ }^{1}$ We refer to techniques rather than systems, because a single system can implement multiple techniques. We will discuss various examples of this.

\section{References}

Allen, T.J. (1977): Managing the Flow of Technology, Cambridge, MA: MIT Press.

Ashbrook, D. and T. Starner (2002): Learning Significant Locations and Predicting User Movement with GPS. Proceedings of IEEE Sixth International Symposium on Wearable Computing (ISWC02). 
Aurigi, A. (2000): Digital City or Urban Simulator? In T. Ishida and K. Isbister (eds.): Digital Cities: Technologies, Experiences, and Future Perspectives. Lecture Notes in Computer Science 1765, New York: Springer-Verlag, pp. 33-44.

Begole J., J. Tang, R. Smith and N. Yankelovich (2002): Work Rhythms: Analyzing Visualizations of Awareness Histories of Distributed Groups. Proceedings of the 2002 ACM Conference on Computer-Supported Cooperative Work (CSCW 2002). New Orleans, USA, Nov. 16-20, ACM Press, NY, pp. 334-343.

Borovoy, R., F. Martin, S. Vemuri, M. Resnick, B. Silverman and C. Hancock (1998): Meme Tags and Community Mirrors: Moving from Conferences to Collaboration. Proceedings of the ACM 1998 Conference on Computer-Supported Cooperative Work (CSCW'98), pp. $159-168$.

Brown, P.J., J.D. Bovey and X. Chen (1997): Context-aware applications: From the Laboratory to the Marketplace, IEEE Personal Communications vol. 4, no. 5, pp. 58-64.

Brown, P. (1995): The Electronic Post-it Note: A Metaphor for Mobile Computing Applications, IEEE Colloquium, Mobile Computing and Its Applications, http://www.cs.ukc.ac.uk/projects/mobicomp/Fieldwork/Papers/.

Burrell, J. and G.K. Gay (2001): E-Graffiti: Evaluating Real-world Use of a Context-aware System, submitted to Interacting with Computers - social issue on universal usability.

Cadiz, J.J., G. Venolia, G. Jancke and A. Gupta (2002): Designing and Deploying an Information Awareness interface. Proceedings of CSCW 2002, pp. 313-323.

Carroll, J.M. and M.B. Rosson (2003): A Trajectory for Community Networks. Special Issue: ICTs and Community Networking, The Information Society, vol. 19, no. 5.

Dahlberg, P., F. Ljungberg and J. Sanneblad (2000): Supporting Opportunistic Communication in Mobile Settings. Extended abstracts of ACM 2000 Conference on Human Factors in Computing Systems.

Dey, A. (1998): Context-aware Computing: The CyberDesk Project. Proceedings of the AAAI 1998 Spring Symposium on Intelligent Environments, Menlo Park, CA: AAAI Press. pp. 51-54.

Dey A., G. Abowd and D. Salber (2001): A conceptual framework and a toolkit for supporting the rapid prototyping of context-aware applications, Special issue on context-aware computing, Human-Computer Interaction (HCI) Journal, vol. 16, no. 2-4, pp. 97-166.

Donath, J., K. Karahalios and F. Viegas (1999): Visualizing Conversations. Proceedings of HICSS-32, Maui, HI.

Erickson, T. (2003): Designing Visualizations of Social Activity: Six Claims. Extended Abstracts of CHI 2003.

Esbjörnsson, M., O. Juhlin and M. Östergen (2003): Mobility: Motorcycling and Social Interaction: Design for the Enjoyment of Brief Traffic Encounters. Proceedings of the 2003 International ACM SIGGROUP Conference on Supporting Group Work.

Espinoza, F., P. Persson, A. Sandin, H. Nyström, E. Cacciatore. and M. Bylund (2001): GeoNotes: Social and Navigational Aspects of Location-Based Information Systems. Proceedings of Ubicomp 2001, pp. 2-17.

Etzioni, A. (1999) The Limits of Privacy, New York: Basic Books.

Franck, K. and L. Schneekloth (1994): Ordering Space: Types in Architecture and Design, New York: Van Nostrand Reinhold. General Design.

Freeman, L. (1998): Computer Programs in Social Network Analysis, Connections, vol. 11, pp. 26-31.

Garfinkel, H. (1967): Studies in Ethnomethodology, NJ: Prentice-Hall.

Garton, L., C. Haythornthwaite and B. Wellman (1997): Studying Online Social Networks. Journal of Computer Mediated Communication vol. 3, no. 1, June: http://www.usc.edu/dept/ annenberg/vol3/issuel/garton.html 
Genereux, R.L., L.M. Ward and J.A. Russell (1983): 'The Behavioral Component in the Meaning of Places', Journal of Environmental Psychology, vol. 3, pp. 43-55.

Gillepsie, A. and H. Williams (1988): Telecommunications and the Reconstruction of Regional Comparative Advantage, Environment and Planning, vol. 20, pp. 1311-1321.

Granovetter, M. (1973): 'The Strength of Weak Ties', American Journal of Sociology, vol. 78, no. (6), pp. 1360-1380.

Griswold, W., G. Shanahan, S. Brown, R. Boyer, M. Ratto, R. Shapiro and T. Truong (2003) ActiveCampus - Experiments in community-oriented ubiquitous computing, Technical Report CS2003-0750, Computer Science and Engineering, UC San Diego (http://wwwcse.ucsd.edu/ wgg/papers.html\#ubi).

Harper, R. (1992): Looking at Ourselves: An Examination of the Social Organisation of Two Research Laboratories. Proceedings of the ACM Conference on Computer-Supported Cooperative Work. November 01-04, 1992, Toronto, Ontario, Canada, pp. 330-337.

Hiltz, S.R. and M. Turoff, The Network Nation: Human Communication via Computer. Addison-Wesley Publishing Company, Inc, London, 1978.

Hightower, J. (2003): From Position to Place. Proceedings of The 2003 Workshop on LocationAware Computing Oct. 2003, pp. 10-12.

Hindus, D., S.D. Mainwaring, N. Leduc, A.E. Hagström and O. Bayley (2001): Casablanca: Designing Social Communication Devices for the Home. Proceedings of CHI 2001 ACM Press, pp. 325-332.

Hong, J. and J. Landay (2004): An Architecture for Privacy-Sensitive Ubiquitous Computing. Proceedings of The Second International Conference on Mobile Systems, Applications, and Services (Mobisys 2004).

Isaacs, E., A. Walendowski and D. Ranganathan (2002): Hubbub: A Sound-Enhanced Mobile Instant Messenger that Supports Awareness and Opportunistic Interactions. Proceedings of CHI 2002, pp. 179-186.

Ishida, T. (2002): Digital City Kyoto: Social Information Infrastructure for Everyday Life. Communications of the ACM, vol. 45, p. 7.

Jones, Q. and S.A. Grandhi (2004): Supporting Proximate Communities with P3-Systems: Technology for Connecting People-To-People-To-Geographical-Places, In: M. weiberg (ed.): The Interaction Society: Practice, Theories, and Supportive Technologies, New York: Idea Group, Inc. (in press).

Jones, Q., S.A. Grandhi, L. Terveen, S. Whittaker and K. Chivakula (2004): Putting Systems into Place: A Qualitative Study of Design Requirements for Location-Aware Community Systems. Proceedings of the ACM's 2004 Conference on Computer-Supported Cooperative Work. New York: ACM Press.

Jones, Q., G. Ravid and S. Rafaeli (2004): Information Overload and the Message Dynamics of Online Interaction Spaces: A Theoretical Model and Empirical Exploration, Information Systems Research: vol. 15, no. 2, pp. 194-210.

Kautz, H., B. Selman and M. Shah (1997): ReferralWeb: Combining Social Networks and Collaborative Filtering, Communications of the ACM, vol. 30, no. 3, March 1997.

Kramer, B. (1995): Classification of Generic Places: Explorations with Implications for Evaluation. Journal of Environmental Psychology, vol. 15, pp. 3-22.

Kraut, R. and L. Streeter (1995): Coordination in Software Development. Communication of the $A C M$, vol. 38, no. 3, pp. 69-81.

Kraut, R., R. Fish, R. Root and B. Chalfonte (1990): Informal Communication in Organizations: Form, Function and Technology. In: R. Baecker, (ed.). Reading in Group-ware and Computer Supported Cooperative Work: Assisting Human to Human Collaboration, San Francisco, CA: Morgan Kaufmann Publishers, pp. 287-314. 
Kraut, R., M. Patterson, V. Lundmark, S. Kiesler, T. Mukhopadhyay, and W. Scherlis (1998): 'Internet Paradox: A Social Technology that Reduces Social Involvement and Psychological Well-being?', American Psychologist, vol. 53, no. 9, pp. 1017-1031.

Langheinrich, M. (2001): Privacy by Design - Principles of Privacy-Aware Ubiquitous Systems. Proceedings of the 3rd International Conference on Ubiquitous Computing. September 30-October 02, 2001, Atlanta, Georgia, USA, pp. 273-291.

Langheinrich, M. (2002): A Privacy Awareness System for Ubiquitous Computing Environments. Proceedings of the 4th International Conference on Ubiquitous Computing. September 29-October 01, 2002, Göteborg, Sweden, pp. 237-245.

Lessig, L. (1998): The Architecture of Privacy. Proceedings of Taiwan NET'98, Taipei, Taiwan.

Marmasse N. and C. Schmandt (2000): Location-aware Information Delivery with ComMotion. in HUC 2000.

McCarthy, J.F., D.H. Nguyen, A.M. Rashid and S. Soroczak (2003): Proactive Displays and The Experience UbiComp Project. Adjunct Proceedings of Ubicomp 2003.

McCarthy, J.S. and E.S. Meidal (1999): ACTIVE MAP: A visualization Tool for Location Awareness to Support Informal Interactions. HUC 1999, pp. 158-170.

McDonald, D.W. (2003): Recommending Collaboration with Social Networks: A Comparative Evaluation. Proceedings of the 2003 ACM Conference on Human Factors in Computing Systems (CHI'03) pp. 593-600. ACM Press.

Milgram, S. (1977): The Individual in a Social World: Essays and Experiments. Reading, Mass: Addison-Wesley Pub. Co.

Nardi, B., S. Whittaker and H. Schwarz (2000): It's Not What You Know, It's Who You Know: Work in the Information Age. First Monday, www.firstmonday.org.

Nelson, L., C.E. Ramsey and C. Verner (1960): Community Structure and Change, New york: The Macmillan Co.

Nodder, C. (2003): Say versus Do; building a trust framework through users' actions, not their words. 2003, Workshop on Ubicomp communities: privacy as boundary negotiation.

Olson, G.M. and J.S. Olson (2000): Distance Matters. Human-Computer Interaction, vol. 15, pp. 139-179.

Palen, L. and J. Grudin (2002): Discretionary Adoption of Group Support Software: Lessons rom Calendar Applications, in B.E. Munkvold (ed.), Implementing Collaboration Technologies in Industry pp. 159-180. Springer Verlag.

Palen, L. and P. Dourish (2003): Unpacking "Privacy" for a Networked World. Proceedings CHI 2003.

Parks, M.R. and L.D. Robert (1998): 'Making MOOsic: The Development of Personal Relationships Online and a Comparison to their Offline Counterparts', Journal of Social and Personal Relationships, vol. 15, pp. 517-537.

Paulos, E. and E. Goodman (2004): The Familiar Stranger: Anxiety, Comfort, and Play in Public Places. Proceedings of CHI'94 Conference on Computer Human Interaction, Vienna, Austria, New York, NY, USA: ACM Press. pp. 223-230.

Reuters/Wired News (1998): Bleep at First Sight: LoveGety http://www.wired.com/news/culture $/ 0,1284,12342,00 \cdot \mathrm{html}$.

Sack, W. (2000): Conversation Map: A Content-Based Usenet Newsgroup Browser. Proceedings of the 2000 International Conference on Intelligent User Interfaces (IUI'2000) New york, NY: ACM Press. pp. 233-240.

Schilit, B., N. Adams and R. Want (1994): Context-aware Computing Applications. Proceedings of the Workshop on Mobile Computing Systems and Applications, Santa Cruz, CA, pp. 85-90.

Schuler, D. (1994): Community Networks: Building a New Participatory Medium. Communications of the $A C M$, vol. 37 , no. 1, pp. 38-51 
Shekhar, S. and S. Chawla (2003): Spatial Databases: A Tour: Prentice Hall.

Smith, M.A. and A.T. Fiore (2001): Visualization Components for Persistent Conversations. Proceedings of the 2001 ACM Conference on Human Factors in Computing Systems (CHI'01), New york, NY: ACM Press, pp. 136-143.

Spohrer, J. (1999): 'Information in Places', IBM Systems Journal, vol. 38, no. (4), pp. 602-625.

Stern, M., (1960): The Eclipse of Community, Princeton, NJ: Princeton University Press.

Straits Times (July 3, 2004): In BEDD with strangers: online newspaper (http://straitstimes.asia1.com.sg/geny/story/0,4386,259731,00.html).

Terry, M., E.D. Mynatt, K. Ryall and D. Leigh (2002): Social Net: Using Patterns of Physical Proximity over Time to Infer Shared Interests. CHI 2002 Extended Abstracts.

Terveen, L. and D. McDonald (forthcoming): Social Matching: A Framework and Research Agenda. Submitted to The ACM's Transactions of Computer Human Interaction.

Turkle, S. (1995): Life on the Screen: Identity in the Age of the Internet. Simon and Schuster Trade.

Walther, J.B. (1992): 'Interpersonal Effects in Computer-mediated Interaction: A Relational Perspective', Communication Research, vol. 19, pp. 52-90.

Walther, J.B., J.F. Anderson and D.W. Park (1994): Interpersonal Effects in Computermediated Interaction: A Meta-analysis of Social and Antisocial Communication, Communication Research vol. 21, pp. 460-487.

Want, R. and A. Hopper (1992): 'Active Badges and Personal Interactive Computing Objects', IEEE Trans. on Consumer Electronics, vol. 38, no. 1, pp. 10-20.

Want, R., A. Hopper, V. Falcao, and J. Gibbons (1992): The Active Badge Location System, ACM Transactions on Information Systems (TOIS) vol. 10, no. 1 pp. 91-102

Wasserman, S. and K. Faust (1994): Social Network Analysis, Cambridge: Cambridge University Press.

Weilenmann, A. and L.E. Holmquist (1999): Hummingbirds Go Skiing: Using Wearable Computers to Support Social Interaction. Proceedings of the IEEE International Symposium on Wearable Computing (ISWC)'99, IEEE Press, 1999.

Wellman, B., A. Quan Haase, J. Witte and K. Hampton (2001): Does the Internet Increase, Decrease, or Supplement Social Capital? Social Networks, Participation, and Community Commitment. In the special issue "The Internet in Everyday Life", American Behavioral Scientist vol. 45, no. 3, pp. 437-456.

Westin, A.F. (1967): Privacy and Freedom. New York, NY: Atheneum, 1967.

Whittaker S., Q. Jones and L. Terveen (2002). Managing Long Term Communications: Conversation and Contact Management. Proceedings of the 35th Annual Hawaii International Conference on System Sciences, IEEE, Big Island, Hawaii.

Whittaker S., Q. Jones, B. Nardi, L. Terveen, M. Creech, L. Terveen, E. Isaacs and J. Hainsworth (Forthcoming) ContactMap: using personal social networks to organize communication in a social desktop: Submitted to The ACM's Transactions of Computer Human Interaction.

Whittaker, S., D. Frohlich and O. Daly-Jones (1994): Informal communication: What is It Like and How Might We Support It? Proceedings of CHI'94 Conference on Computer Human Interaction, Boston, USA, C. Plaisant (ed.): New york NY: ACM Press, pp. 130 137.

Whyte, W. H. (1956): The Organization Man, New York: Simon and Schuster.

Wiberg, M. (2001): RoamWare: An Integrated Architecture for Seamless Interaction in Between Mobile Meetings. Proceedings of the 2001 International ACM SIGGROUP Conference on Supporting Group Work. Boulder, Colorado CO: ACM Press, pp. 288-297.

Wiberg, M. (2004): FolkMusic: A Mobile Peer-to-Peer Entertainment System. HICSS37, Hawaii, USA. 